\title{
Design Criteria for Combat Boots Based on the Evaluation and Analysis of Human Factors
}

\author{
Laura Lucía PEREZ ${ }^{* a}$, Ana María POLANCO ${ }^{a}$, Alejandro MARANON ${ }^{a}$ \\ ${ }^{a}$ Department of Mechanical Engineering. Universidad de los Andes. Colombia.
}

\begin{abstract}
Currently there is not an anthropometric foot database for Colombian military population. Due to this fact, health problems with sizing of combat boots have been found. Inadequate footwear causes different epidemiological feet diseases and deformations. A Foto Scan 3D manufactured by Precision 3D (United Kingdom), was used to acquire digital models from 75 Colombian soldiers. Fifteen anthropometric measurements were extracted from each foot using two programs: the measurement tool from the Foto Scan software and Rhinoceros 4.0. Results from this process were all the statistical values and percentiles of the anthropometric measurements.
\end{abstract}

Keywords: Foot, 3D model, 3D scanner, anthropometric measurements.

\section{Introduction}

Boots are one of the most important garments used by the military. However, sometimes their geometric features and sizing hampers health of low extremities. Therefore, studies to find a better interaction between the foot and the footwear are relevant.

Assessment of footwear is important as many feet health problems are associated with coverings, geometrical shapes and other factors that can lead to discomfort, pain, and reduction or loss of mobility. An effective footwear assessment depends on the ability to differentiate a suitable or unsuitable shoe. To do this, it is necessary to understand the function of the different shoe parts and the properties of the materials used in its construction.[1]

Although, having information of boot's materials and components is important, gathering feet anthropometric data is even more imperative. Feet have important functions such as: supporting body weight, leverage to push the body, and load cushioning, which somehow affect feet if footwear is not adequate. In military footwear design, two important factors must be taken into consideration: (1)The environmental conditions in the tropical forest that creates an appropriate environment for bug infections, humidity and bad hygiene situation, and (2) the excessive weight carried, which creates a burden transmitted to the skeletal system, mainly on the heels and forefoot, stimulating a incidence of injury due to the shock during heel strike stance [2].

One of the most difficult tasks nowadays is to boost up the relationship among environment, human body and protection systems to develop products design criteria. The analysis of human factors to improve protection, comfort and hygiene is mandatory, because it brings up into the design factors that are usually not evident such as allergies. Human factors analysis helps to clarify some of the causes of the injuries, traumas, pathologies, and physiological effects caused by wearing of improper footwear.

Specific problems of the combat boots are: sizes and moisture. The former, sizes are not derived from anthropometric measurements. The latter; inadequate moisture inside the boot, which creates a suitable environment for fungal growth. This paper details the first step towards the creation of a Colombian anthropometric database with fifteen different foot parameters (measurements) from military population who must wear combat boots daily. Measurements were obtained with a Foot 3D FotoScan, which creates instant digital casts from photos of the feet. A total of 150 feet were analyzed.

\section{Methods and equipment}

\subsection{Foot anthropometric measurements}

This study follows the ISO7250 standard, which defines two parameters on the foot: foot length and foot breadth. During this investigation it was determined that more parameters should be included in the foot database to guarantee an improvement in high performance combat boots design, therefore biomechanical aspect were studied. 
Additionally, apart from foot length and breadth, another measures were incorporated into the research, in order to provide designers with additional criteria for boot design.

Taking into account these two aspects the measures extracted from the digital models are those detailed in Table 1

Table 1. Anthropometric foot measurements

\begin{tabular}{l}
\hline \multicolumn{1}{c}{ Measurement } \\
\hline Foot Length \\
Instep Length \\
Fibular instep length \\
Heel breadth \\
Diagonal foot breadth \\
Length from the longest toe to the point $\mathrm{F}$ \\
Lateral malleolus height \\
Great toe height \\
Arch height \\
Plantar vault height \\
Bimalleolar circumference \\
Instep circumference \\
Heel circumference \\
Diagonal ankle circumference \\
Foot circumference \\
\hline
\end{tabular}

Table 2 and Fig. 1, presents the points of reference used to obtain the foot measurements listed above. These points correspond to foot bones that are in contact with footwear.

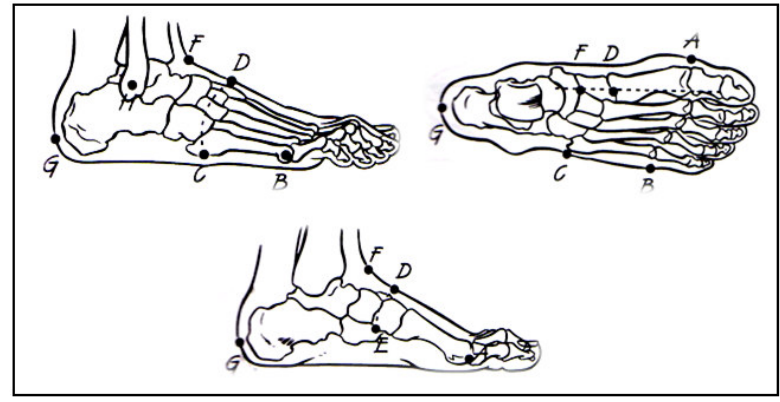

Fig. 1. Reference points on the foot.[3]

Table 2. Points of reference for measurements

\begin{tabular}{cl}
\hline Point Reference & \multicolumn{1}{c}{ Name of the point } \\
\hline A & First metatarsal head \\
B & Fifth metatarsal head \\
C & Fifth metatarsal styloid \\
D & At the height of the C point, an outline is traced on \\
& the dorsal foot. The highest point is D. \\
E & Bottom apophysis of the first cuneiform bone \\
F & Point where leg becomes the foot \\
G & Rear heel \\
H & Most prominent point of lateral malleolus \\
\hline
\end{tabular}

The measures extracted from the 3D digital models were:

\subsubsection{Foot Length (1)}

Foot length changes while a person is walking. In footwear design, it is used to prevent boot tightness or looseness. Tightness, for example, could be responsible for "shoe dermatitis" as the skin is in contact with a vast variety of potentially sensitizing chemicals used during shoe manufacturing and finishing [4]. 
2.1.2. Instep Length (2) and Fibular instep length (3)

The fibular instep length and the instep length are very important as the axis of bending for the sole depends on all of these measurements [5]. (see Fig. 2).

\subsubsection{Heel breadth (4)}

Indicates the space required to hold the adipose tissue that covers the heel. This tissue cushions shocks due to the presence of fibroelastic tissue and fat cells [6]. (see Fig. 2)

\subsubsection{Diagonal foot breadth (5)}

This parameter is important on the terminal double limb stance part of the gait cycle because this is the moment in which the forefoot reaches its maximum width. Using a narrow shoe can cause thickening of the epidermis and inflammatory reactions in the subcutaneous tissue leading to foot deformity [3].

\subsubsection{Length from the longest toe to the point $F(6)$}

This measurement is important for the range of movement of the foot through the ankle joint that permits dorsiflexion and plantarflexion (see Fig. 2).

\subsubsection{Lateral malleolus height (7)}

This measure estimates approximately where ankle rotation axis is located (see Fig. 2).

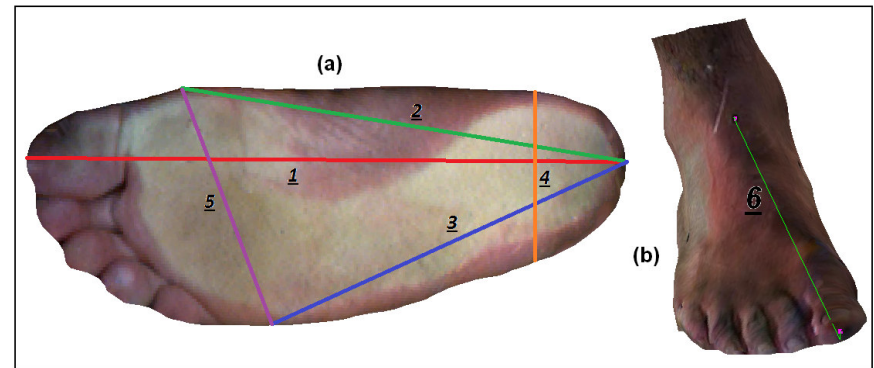

Fig. 2. (a) Longitudinal measures 1-5 (b) Measure 6

2.1.7. Great toe height (8)

For the safety of the toes and toenails is important to know the height of the great toe to assure the free movement of the toes inside the shoe (see Fig. 3).

\subsubsection{Arch height (9)}

This measure is important in footwear design due to two aspects: First, the movement of dorsiflexion and plantarflexion of the foot, and second, the extensor hallucis that helps to extend the hallux.

\subsubsection{Plantar vault height (10)}

This measure is one of the main parameters for the construction of insoles, as it indicates if a person displays pes cavus (high instep), pes planus (flat feet) or normal foot.

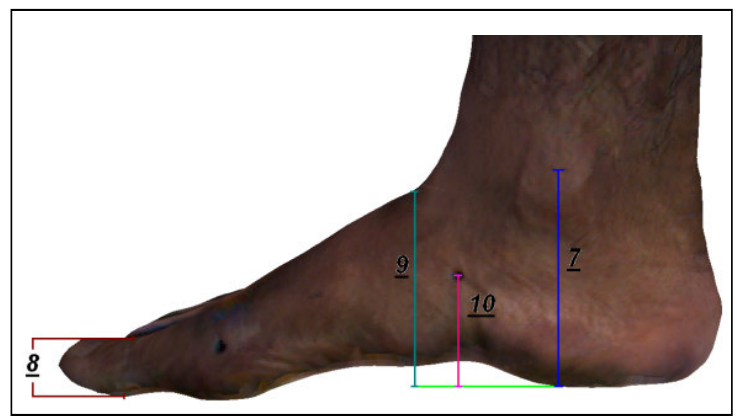

Fig. 3. Heights 7-10 


\subsubsection{Circumferences}

Foot circumferences measured were: foot circumference (11), instep circumference (12), diagonal ankle circumference (13), heel circumference (14), and bimalleolar circumference (15). These measures are related to the proper design and cutting pattern of the material that will cover the foot, and the location of the lace-anchors and systems that helps to tighten footwear (see Fig. 4).

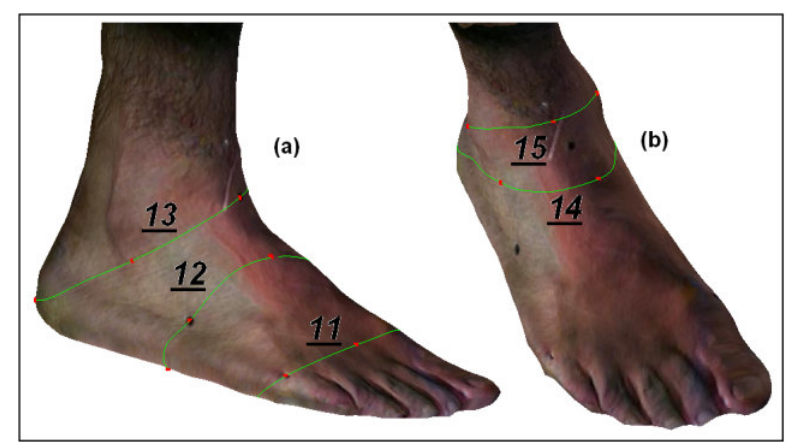

Fig. 4. (a) Circumferences 11-13, (b) Circumferences 14 and 15

\section{Measurement procedure}

\subsection{Informed consent and personal history information form}

Subjects were provided with both an informed consent, and a personal history forms. The informed consent described the purpose of the study, the anthropometric measurement process, and the equipment used. The informed consent also clearly explained the freedom of the subject to decide about his participation in the study.

\subsection{Scanning process}

When the subject decided to participate, bones marks were located on both bare feet and the scanning process then took place. The person has to stand on balance on the platform and put one of their feet on the glass of the scanner for about four seconds. The scanner used was the Foot FotoScan3D manufactured by Precision 3D (United Kingdom)

\section{Measurements extraction}

\subsection{Measurement software}

Feet were post processed using FotoScan 3D and Rhinoceros 4.0 software. Table 3 indicates what measures were obtained with each software.

Table 3. Software program used for each measurement

\begin{tabular}{lc}
\hline \multicolumn{1}{c}{ Measurement } & Software program \\
\hline Foot Length & Foto Scan 3D \\
Instep Length & Foto Scan 3D \\
Fibular instep length & Foto Scan 3D \\
Heel breadth & Foto Scan 3D \\
Diagonal foot breadth & Foto Scan 3D \\
Length from the longest toe to the point F & Foto Scan 3D \\
Lateral malleolus height & Rhinoceros 4.0 \\
Great toe height & Rhinoceros 4.0 \\
Arch height & Rhinoceros 4.0 \\
Plantar vault Height & Foto Scan 3D \\
Circumferences & Rhinoceros 4.0 \\
\hline
\end{tabular}

\subsubsection{Foto Scan $3 D$}

The FotoScan 3D software includes a measurement feature that allows taking a range of measures from 3D models obtained by the scanner. Measures supported are as follows:

2D lines measures,

$3 \mathrm{D}$ cross section measures,

3D lines measures. 
During this study, only 2D line measures were used. This as a result of some repeatability issues found when 3D line measures were used. The types, names and number of measurements available are determined by the "measurements" file in the FotoScan 3D folder. This is a simple text file containing a measurement "label" an a measurement type.

\subsection{Data processing}

Having all the measurements extracted, statistics were made following the general requirements for the anthropometric database according to the standard ISO15535:2003. MSExcel was used to analyze the anthropometric data, and obtaining the following statistics values:

- Number of subjects.

- Minimum

- Maximum

- Arithmetic mean.

- Standard error of the mean.

- Standard Deviation.

- Coefficient of variation.

- Frequency Distribution.

- Skewness.

- Kurtosis.

- Percentiles, $1^{\text {st }}$ to $99^{\text {th }}$. The percentile values were calculated from the experimental distribution of individual subjects in the sample rather than estimated from a theoretical Gaussian distribution.

\section{Results}

\subsection{Anthropometric database}

Due to the delicate nature of the study, privacy issues prevent the authors from showing the full anthropometric tables. Some of the statistical values for right and left foot (separately) are shown in Table 4. For further information, please contact corresponding author.

Table 4. Statistical values for the fifteen measurements

\begin{tabular}{|c|c|c|c|c|c|c|}
\hline \multirow{2}{*}{$\begin{array}{c}\text { Measurement } \\
\text { Foot }\end{array}$} & \multicolumn{2}{|c|}{ Minimum (mm) } & \multicolumn{2}{|c|}{ Maximum (mm) } & \multicolumn{2}{|c|}{ Coefficient of Variation } \\
\hline & $\mathbf{R}$ & $\mathbf{L}$ & $\mathbf{R}$ & $\mathbf{L}$ & $\mathbf{R}$ & $\mathbf{L}$ \\
\hline Foot length & 238,0 & 236,0 & 284,0 & 281,0 & $4,2 \%$ & $4,0 \%$ \\
\hline Heal breath & 57,0 & 60,0 & 79,0 & 80,0 & $6,2 \%$ & $6,5 \%$ \\
\hline Instep length & 178,0 & 173,0 & 216,0 & 213,0 & $4,6 \%$ & $4,4 \%$ \\
\hline Diagonal foot breadth & 85,0 & 84,0 & 107,0 & 109,0 & $5,3 \%$ & $5,4 \%$ \\
\hline Fibular instep length & 153,0 & 135,0 & 200,0 & 202,0 & $5,2 \%$ & $6,2 \%$ \\
\hline Plantar vault height & 31,0 & 27,0 & 65,0 & 73,0 & $16,0 \%$ & $20,6 \%$ \\
\hline Length from the longest toe to the point $F$ & 143,0 & 142,0 & 186,0 & 184,0 & $5,7 \%$ & $6,0 \%$ \\
\hline Bimalleolar circumference & 232,0 & 234,0 & 311,0 & 320,0 & $5,6 \%$ & $5,9 \%$ \\
\hline Lateral malleolus height & 54,0 & 58,0 & 83,0 & 82,0 & $8,6 \%$ & $7,9 \%$ \\
\hline Instep circumference & 222,0 & 222,0 & 270,0 & 272,0 & $4,9 \%$ & $4,7 \%$ \\
\hline Heel circumference & 322,0 & 314,0 & 400,0 & 399,0 & $5,2 \%$ & $5,2 \%$ \\
\hline Diagonal ankle circumference & 293,0 & 284,0 & 352,0 & 353,0 & $4,7 \%$ & $4,8 \%$ \\
\hline Arch height & 61,0 & 61,0 & 88,0 & 88,0 & $6,4 \%$ & $7,5 \%$ \\
\hline Great toe height & 13,0 & 12,0 & 26,0 & 28,0 & $15,4 \%$ & $20,4 \%$ \\
\hline Foot circumference & 216,0 & 218,0 & 272,0 & 269,0 & $5,1 \%$ & $4,5 \%$ \\
\hline
\end{tabular}


To compare the measurements obtained in this study, a Latin American foot database of measures from soldiers obtained in the period 1965-1970 for the NASA was analyzed. The Table 5 shows the differences in millimeters between the arithmetic means of both studies.

Table 5. Databases comparisons

\begin{tabular}{lc}
\hline \multicolumn{1}{c}{ Measurement } & Arithmetic Mean $(\mathbf{m m})$ \\
\hline \multicolumn{1}{c}{ Database } & NASA against Colombian \\
Foot circumference & 3 \\
Foot breadth & 0.6 \\
Foot length & 3.6 \\
Diagonal ankle circumference & 9.6 \\
Heel breath & 1.9 \\
Instep circumference & 5.6 \\
Instep length & 6.3 \\
\hline
\end{tabular}

The larger differences between these databases are in the circumferences, the diagonal ankle circumference and the instep circumference.

\subsection{Number of subjects for sizing}

Based on the standard ISO 15535, the sample size has to be sufficient for the purposes of investigation. In most cases, anthropometric data for technological design are of interest in the $5^{\text {th }}$ and $95^{\text {th }}$ percentiles. The method given by the standard to find the $\mathrm{N}$ needed subjects to ensure that the database will be between $5^{\text {th }}$ and $95^{\text {th }}$ percentiles with a $95 \%$ confidence and a percentage of relative accuracy is calculates using the equation 1: [7]

$$
N=\left(\frac{1.96 \times C V}{a}\right)^{2} \times 1,534^{2} \quad(1) \quad C V=\frac{S D}{\bar{x}} \times 100
$$

where 1.96 is the critical value ( $z$ value) from a standard normal distribution for a $95 \%$ confidence interval, $\mathrm{CV}$ is the coefficient of variation showed in the equation $2, \bar{x}$ is the arithmetic mean and SD is the standard deviation of the population for the body dimension in question. In this particular case, there are 13 variables with their own CV, as shown in Table 6.

\begin{tabular}{lll} 
Table 6. Method for estimating the number of subjects needed on a sample \\
\cline { 2 - 3 } \multicolumn{1}{c}{ Measurement } & CV & N \\
\hline Foot length & 4,1 & 172,0 \\
Heal breath & 6,4 & 405,3 \\
Instep length & 4,5 & 205,0 \\
Diagonal foot breadth & 5,3 & 283,3 \\
\hline Fibular instep length & 5,7 & 324,9 \\
\hline Plantar vault Height & 5,7 & 330,9 \\
Length from the longest toe to the point F & 5,8 & 340,0 \\
Bimalleolar circumference & 5,7 & 330,9 \\
Instep circumference & 4,8 & 229,5 \\
\hline Heel circumference & 5,2 & 267,9 \\
Diagonal ankle circumference & 4,7 & 225,3 \\
\hline Arch height & 6,9 & 479,5 \\
Foot circumference & 4,8 & 232,0 \\
\hline
\end{tabular}

According to the Table 6 the sample size is 480 subjects.

\subsection{Epidemiological Studies}

The epidemiological studies revealed cause-effect relationships that allow the establishment of design criteria aimed at minimizing the harmful effects of footwear to improve the health of users. In this study, through the pictures of the feet some characteristics were determined (see Table 7). 


\begin{tabular}{|c|}
\hline $\begin{array}{c}\text { Characteristics analyzed } \\
\text { on soldiers feet }\end{array}$ \\
\hline Hallux Valgus \\
\hline Calluses \\
\hline Hammer toes \\
\hline Foot type \\
\hline Skin fungus \\
\hline Dry skin \\
\hline Dermatphytosis \\
\hline Dermatitis \\
\hline
\end{tabular}

\subsubsection{Hallux valgus (bunion)}

This abnormality is a deformity of the bone or tissue around the metatarsophalngeal joint, at the base of the big toe. This is a painful deformity due to the tissues surrounding the joint may be swollen and tender [8]. In this study $63.6 \%$ of the subjects suffered of this condition, and $20 \%$ had deformities on the first and fifth joint. Only the $17.3 \%$ did not have any of these anomalies.

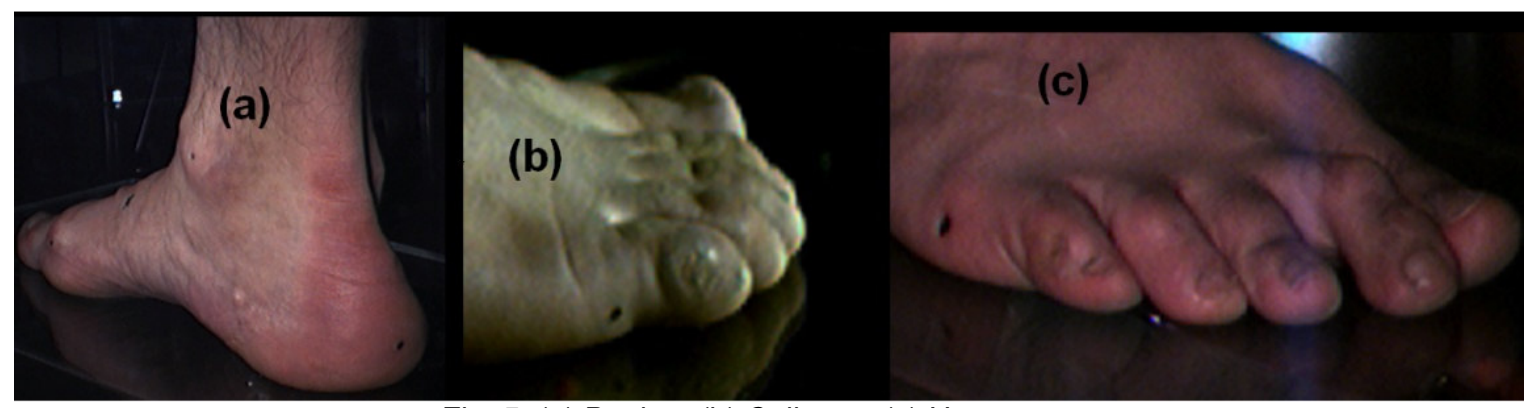

\subsubsection{Calluses}

Fig. 5. (a) Bunion, (b) Calluses, (c) Hammer toe

Callosities are acquired areas of thickened skin that appear over sites of repeated or prolonged trauma to the epithelium. These lesions arise because of pressure, friction, and shearing forces of bone against adjacent digits, metatarsal heads, or footwear. They are associated with poorly fitting footwear, underlying anatomic deformities, and high levels of activity [9]. In this study there were:

- $63.6 \%$ calluses on the fifth phalange

- $29.3 \%$ calluses on the forth phalange

- $22.6 \%$ calluses on the third phalange

- $18.2 \%$ calluses on the second phalange

- $49.3 \%$ calluses on the first phalange

- $6.6 \%$ calluses under the ball of the foot

- $66.6 \%$ calluses on the heel

- $32 \%$ calluses on the instep, increasing instep circumference length

\subsubsection{Hammer toes}

The hammer toe deformity results from the progressive loss of flexibility of the extensor tendons or the toes and it is a specific cause of metatarsalgia. The bent position of the toe results frequently from wearing shoes that are too short or narrow for the foot [6]. In here $34.6 \%$ of the subjects had this deformity. The Fig. 5. (c ) shows the second phalange as a hammer toe.

\subsubsection{Foot type}

The Fig. 6 shows four pictures of the plantar surface of 4 soldiers with different type feet. The percentages found examining the bottom pictures were:

- $10.6 \%$ Flat feet

- $10.6 \%$ Pes cavus grade II

- $2.6 \%$ Pes cavus grade I

- $76 \%$ Normal feet 


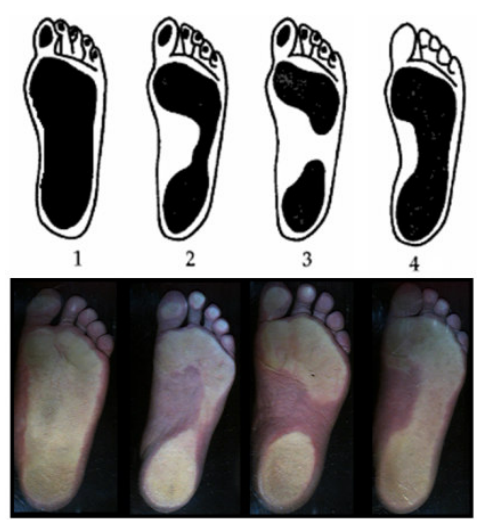

Fig. 6. Foot type (1) Flat foot, (2) Pes cavus grade II (3) Pes cavus grade I (4) Normal foot

\subsubsection{Skin fungus}

$20 \%$ of the subjects had skin fungus; the Fig. $7 c$ shows a sole of the infected foot.

\subsubsection{Dry skin}

$56 \%$ of the subjects had dry skin on their feet. Mostly on the sole and heel.

\subsubsection{Dermatophytosis}

This fungal infections are caused by a group of fungi known as tinea or dermatophytes that affect among other parts of the body, the feet. $50.7 \%$ of the feet analyzed presented dermatophytosis conditions.

\subsubsection{Dermatitis}

Just $2.7 \%$ of the feet analyzed showed dermatitis conditions, the Fig. 7 (d) is the foot of a person with little blisters.
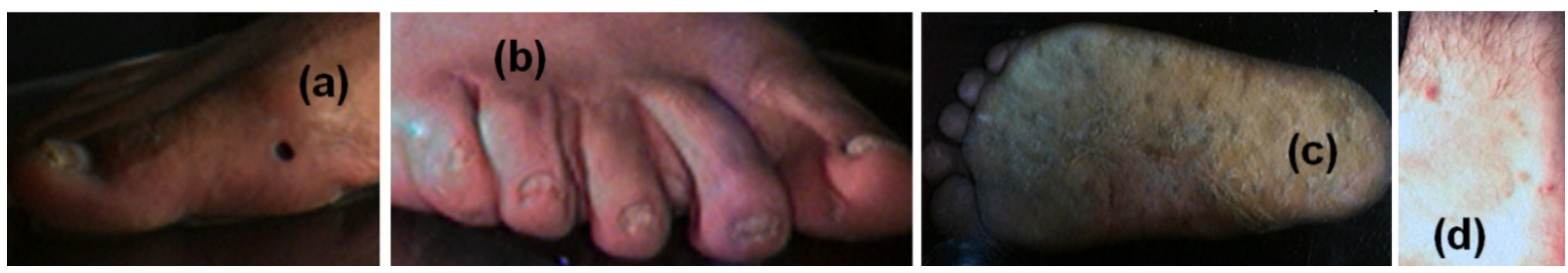

Fig. 7. (a,b)Dermatophytosis, (c)Skin fungus, (d) Dermatitis

\section{Conclusions}

The first 150 feet were measured, completing $15.6 \%$ of the anthropometric database for the Colombian military personnel, 15 measurements were processed and 8 characteristics analyzed.

From standard ISO 7250 two measurements were obtained, foot length and foot breath; the other 13 measures were selected based on biomechanical analysis of the foot.

A significant sample size for a correct estimation of population parameters, the statistical values and the percentiles for the anthropometric database, were calculated and reported based on the standard ISO 15535.

The comparison with the NASA database showed that there is similarity between the length measurements, but a notable difference between some circumferences of the feet. 


\section{Acknowledgements}

The research presented in this paper was funded by the Military Industry of Colombia (INDUMIL), through contract CIFI-4036.

\section{References}

1. Merriman, L. and W. Turner, Assessment of the lower limb. 2002: Elsevier Health Sciences.

2. Lindgren, $U$. and A. Seireg, The influence of mediolateral deformity, tibial torsion, and foot position on femorotibial load. Archives of Orthopaedic and Trauma Surgery, 1989. 108(1): p. 22-26.

3. International Organization For Standardization, ISO 7250-1 Basic human body measurements for technological design. 2008: Geneva, Switzerland.

4. Smith, R., Shoe dermatitis: A review of current concepts. The Foot, 2008.

5. Viel, E. and G. Asencio, La marcha humana, la carrera y el salto: biomecánica, exploraciones, normas y alteraciones. 2002.

6. Simon, R. and S. Koenigsknecht, Emergency orthopedics: the extremities. 2001: McGraw-Hill Professional.

7. Ramiro, J., et al., Guía de recomendaciones para el diseño de calzado. Valencia: Instituto de Biomecánica de Valencia, 1995.

8. 3D, P., The FotoScan 3D(tm) Foot Scanner - a comprehensive foot scanning and measurement system.

9. International Organization For Standardization, ISO 15535. General requirements for stablishing anthropometric databases. 2006: Geneva, Switzerland.

10. Izquierdo, J., Cirugia Podologica. 2006: Elsevier España.

11. Arndt, K. and J. Hsu, Manual of dermatologic therapeutics. 2007: Lippincott Williams \& Wilkins.

12. Anderson, B., Office orthopedics for primary care: treatment. 2006: WB Saunders Co. 